\title{
The Role of Macrophage Polarization in Infectious and Inflammatory Diseases
}

\author{
Adam C. Labonte, Annie-Carole Tosello-Trampont, and Young S. Hahn*
}

\begin{abstract}
Macrophages, found in circulating blood as well as integrated into several tissues and organs throughout the body, represent an important first line of defense against disease and a necessary component of healthy tissue homeostasis. Additionally, macrophages that arise from the differentiation of monocytes recruited from the blood to inflamed tissues play a central role in regulating local inflammation. Studies of macrophage activation in the last decade or so have revealed that these cells adopt a staggering range of phenotypes that are finely tuned responses to a variety of different stimuli, and that the resulting subsets of activated macrophages play critical roles in both progression and resolution of disease. This review summarizes the current understanding of the contributions of differentially polarized macrophages to various infectious and inflammatory diseases and the ongoing effort to develop novel therapies that target this key aspect of macrophage biology.
\end{abstract}

\section{INTRODUCTION}

Macrophages $(\mathrm{M} \phi)$ represent a ubiquitous yet complex and nuanced population of immune cells that play essential roles in both disease and homeostasis throughout the body (Hume, 2008). In addition to monocytes and $M \phi$ circulating throughout the bloodstream, specialized tissue-resident $\mathrm{M} \phi$ can be found in most major organs, including Kupffer cells in the liver, Langerhans cells in the skin, microglia in the brain, splenic red pulp $M \phi$, lung alveolar $\mathrm{M} \phi$, adipose tissue $\mathrm{M} \phi$, and bone osteoclasts, to name a few (Davies et al., 2013; Gautier et al., 2012; Ji et al., 2013; You et al., 2013). While some identify these populations as the endpoint of bone marrow monocyte maturation, several lines of evidence indicate that tissue resident $M \phi$ originate during embryogenesis in association with their specific tissue independently from blood monocytes and monocytes/ $\mathrm{M} \phi$ recruited to sites of inflammation (Davies et al., 2013; Gomez and Geissmann,

Department of Microbiology, Beirne B. Carter Center for Immunology Research, University of Virginia, USA

${ }^{*}$ Correspondence: ysh5e@ virginia.edu

Received 14 December, 2013; accepted 16 December, 2013; published online 12 March, 2014

Keywords: cancer, infectious disease, M1 M2, macrophage polarization, NASH/Obesity
2013; Schulz et al., 2012). Regardless of their location, $\mathrm{M} \phi$ are responsible for the maintenance of healthy tissues through phagocytic clearance of apoptotic cells and foreign materials and through tissue repair and remodeling during wound healing (Duffield, 2005; Ghavami et al., 2014; Majai et al., 2014; Mantovani et al., 2013). M $\phi$ are also major regulators of the inflammatory response to disease and infection, acting as a bridge between innate and adaptive immunity by monitoring the microenvironment through an array of surface receptors and secreting appropriate cytokines and chemokines (Heydtmann, 2009; Schwabe et al., 2006).

Depending on the stimuli they encounter, tissue resident and circulatory M $\phi$ populations can be directed to distinct phenotypic programs in a process known as $M \phi$ polarization (Fig. 1, Table 1). The diverse properties of different $M \phi$ subsets can have drastic effects on health and disease within the tissues where they reside; while the induction of a particular subset can be protective during homeostasis or disease, this process can be altered or subverted to enhance pathogenesis and disease progression (by, for example, inappropriately dampening the immune response or exacerbating harmful inflammation) (Murray and Wynn, 2011). Therefore, this review aims to summarize recent findings regarding the identity, properties, and roles of polarized $\mathrm{M} \phi$ in various disease models and the development of therapeutic strategies that target both the process of $M \phi$ polarization and individual $\mathrm{M} \phi$ subsets.

\section{PHENOTYPIC POLARIZATION OF MФ}

The most well-described and commonly reported paradigm of $\mathrm{M} \phi$ polarization is the $\mathrm{M} 1 / \mathrm{M} 2$ polarization axis (Mantovani et al., 2004; Martinez et al., 2009; Sica et al., 2013). Originally named to reflect relationships to Th1/Th2 polarization of immune responses, M1 and M2 M $\phi$ are also referred to as classically or alternatively activated $M \phi$, respectively (Gordon, 2003; Mills et al., 2000).

Classical activation is stimulated by microbial products and proinflammatory cytokines (IFN $\gamma$ and/or LPS or TNF), and the resulting $\mathrm{M} 1 \mathrm{M} \phi$ are characterized by high antigen presentation, high production of IL-12 and IL-23, and high production of nitric oxide (NO) and reactive oxygen intermediates (ROI) (Verreck et al., 2004). M1 M $\phi$ have been shown to produce several other inflammatory cytokines like TNF $\alpha$; IL-1, -6, and -12; Type I IFN CXCL1-3, 5 and 8-10; CCL2-5 and 11; CXCL16; and CX3CL1 (Mantovani et al., 2004; Sica and Mantovani, 2012).

By contrast, alternative/M2 activation is mediated by IL-4, IL- 
Macrophage Polarization in Disease

Adam C. Labonte et al.

Table 1. SR, scavenger receptor; MR, mannose receptor; HO-1, heme oxygenase-1; VEGF, vascular endothelial growth factor; SD-1, sulfiredocin-1; TR-reductase, thioredoxin-reductase (Kadl et al., 2010; Leitinger and Schulman, 2013; Murray and Wynn, 2011)

\begin{tabular}{|c|c|c|c|}
\hline Polarization state & Gene expression & Cytokines & Chemokines \\
\hline M1 & $\begin{array}{c}\text { CD80, CD86, MHC I/II, IL-1R I, TLR2, } \\
\text { TLR4, iNOS }\end{array}$ & $\begin{array}{l}\text { TNF } \alpha, \text { IL-1, IL-6, IL-12, IL-15, IL-23, } \\
\text { ROS, iNOS, type I IFN }\end{array}$ & $\begin{array}{l}\text { CXCL1-3, CXCL5, CXCL8-10, } \\
\text { CXCL16, CCL2-5, CCL8, CCL11, } \\
\text { CCL15, CCL20, CX3CL1 }\end{array}$ \\
\hline M2a & $\begin{array}{l}\text { CD163, MHC II, SR, CD206, MR, } \\
\text { IL-1R II, YM-1, Fizz1, Arg-1 }\end{array}$ & IL-10, TGF $\beta$, IL-12, IL-1Ra & $\begin{array}{l}\text { CCL1, CCL2, CCL24, CCL22, } \\
\text { CCL17, CCL18 }\end{array}$ \\
\hline M2b & CD86, MHC II & IL-10, IL-1, TNF $\alpha$, IL-6 & $\begin{array}{c}\text { CCL1, CCL20, CXCL1, CXCL2, } \\
\text { CXCL3 }\end{array}$ \\
\hline M2c & CD163, TLR1, MR, Arg-1, YM-1, TLR8 & IL-10, TGF $\beta$ & CCL16, CCL18 \\
\hline M2d & VEGF & IL-10, VEGF & CCL5, CXCL10, CXCL16 \\
\hline M4 & $?$ & $\mathrm{TNF} \alpha$ & CCL18, CCL20 \\
\hline Mhem & $\mathrm{HO}-1$ & IL-10 & $?$ \\
\hline $\mathrm{MOx}$ & HO-1, SD-1, TR-reductase & $?$ & $?$ \\
\hline
\end{tabular}

10 , and IL-13, which were initially thought to produce "deactivated $\mathrm{M} \phi$ " (Martinez et al., 2009). M2 M $\phi$ are marked by the upregulation of several surface molecules including Dectin-1, DC-SIGN, mannose receptor (MRC1/CD206), scavenger receptor A (CD204), scavenger receptor B-1, CD163, CCR2, CXCR1, and CXCR2 (Gordon, 2003; Mantovani et al., 2004; Martinez et al., 2009). M2 M $\phi$ exhibit altered cytokine and chemokine production, and typically produce high levels of IL-10 and low levels of IL-12 (Mosser, 2003). CCL1, CCL2, CCL17, CCL18, CCL22, CCL24, and IL-1Ra are also made by alternatively activated $\mathrm{M} \phi$ (Mantovani et al., 2004). Genetic studies of $\mathrm{M} 2 \mathrm{M} \phi$ in mouse models have identified additional signatures of alternative activation, including arginase 1 (Arg1), YM1 (a member of the chitinase family) and FIZZ1 (found in inflammatory zone 1, RETNLA) (Raes et al., 2002; 2005). Generally, the M2 polarization state is characterized by little to no secretion of proinflammatory cytokines, increased secretion of anti-inflammatory cytokines, enhanced scavenging of cellular debris, promotion of tissue remodeling and repair, and, in some cases, increased capacity to fight parasitic infections (Alfano et al., 2013). Additionally, the concept of resolution of inflammation has evolved and is no longer perceived as a passive process that simply occurs when the insult disappears, but rather as a highly orchestrated response coordinated by a complex regulatory network of cells and anti-M1 mediators called pro-resolving mediators (Rius et al., 2012).

$\mathrm{M} 2 \mathrm{M} \phi$ can be further divided into subtypes according to their inductive stimuli and secreted chemokines (Martinez et al., 2008). M2a M $\phi$ are stimulated by IL- 4 and IL-13 and produce CCL24, CCL22, CCL17, and CCL18, which are recognized by CCR3, CCR4, and CCR8 and promote recruitment of eosinophils, basophils, and Th2 cells. M2b M $\phi$ result from activation with immune complexes and TLR agonists (like LPS) and produce CCL1, which recruits Tregs. IL-10 drives $M \phi$ polarization to M2c cells, which produce CCL16 and 18, recruiting eosinophils and naïve $T$ cells, respectively. $\mathrm{M} 2 \mathrm{~d} M \phi$ accumulate in the tumor microenvironment and present an IL-10 ${ }^{\text {hi }}$ EGF $^{\text {hi }}$ M2 profile, but also exhibit some M1 characteristics such as expression of INF $\gamma$-inducible chemokines CCL5, CXCL10, and CXCL16 (Duluc et al., 2009).

A full understanding of the M1/M2 paradigm of $\mathrm{M} \phi$ polarization, however, contains some caveats. First, M1 and M2 M $\phi$ as defined in the foundational literature most likely do not exist as distinct categories, but rather should be considered as extremes at either end of a continuum of overlapping functional states (Mosser and Edwards, 2008). Indeed, M $\phi$ with combinations of M1 and M2 markers can be found in atherosclerotic plaques and some murine tumors (Kadl et al., 2010; Umemura et al., 2008). Second, unlike the irreversible phenotypic changes seen in lymphocytes after exposure to polarizing cytokines, $\mathrm{M} \phi$ polarization is both transient and plastic (Biswas and Mantovani, 2010; Biswas et al., 2008; Sica et al., 2013; Stout and Suttles, 2004). For example, $M 2 M \phi$ can be reprogrammed to express M1 genes following exposure to TLR ligands or IFN $\gamma$ (Mylonas et al., 2009; Stout et al., 2005). Finally, while there is partial overlap of M1-and M2-identifying markers in murine and human studies, there are still markers in each system that fail to translate to the other. The chitinase-like proteins YM1 and YM2, along with $\mathrm{FIZZ1}$, are markers of murine M2 polarization which lack human orthologs, while CCL14, CCL18, and CCL23 are human-restricted M2 markers with no murine orthologs (Chang et al., 2001; Martinez et al., 2009; Raes et al., 2002). Finally, there are other specially activated $\mathrm{M} \phi$ (M4, Mhem, and Mox) that have been described in atherosclerosis and may lie on a separate activation axis from M1/M2 M $\phi$ (Fig. 1). These atherosclerotic $M \phi$ subsets have been discussed in recent reviews (Fenyo and Gafencu, 2013; Leitinger and Schulman, 2013), but will not be examined in detail here.

\section{SIGNALING PATHWAYS INVOLVED IN M $\Phi$ POLARIZATION}

The network of molecular mediators that regulate M1/M2 polarization in response to various stimuli is incompletely understood, but several signaling pathways have been implicated in this process (Fig. 2). One of the major pathways identified is the JAK/STAT pathway, which mediates responses to a collection of different cyotkines and growth factors and regulates processses from hematopoiesis and immune development to lactation and adipogenesis (Rawlings et al., 2004). Binding of IFN $\gamma$ to its cell surface receptor leads to activation of receptor-associated JAKs, which in turn cause STAT1 to dimerize and translocate to the nucleus where it initiates transcription of genes that promote M1-associated functions like enhanced microbicidal activity and proinflammatory cytokine production ( $\mathrm{Hu}$ et al., 2007; Rauch et al., 2013). M $\phi$-specific deletion of SOCS3, an inhibitor 


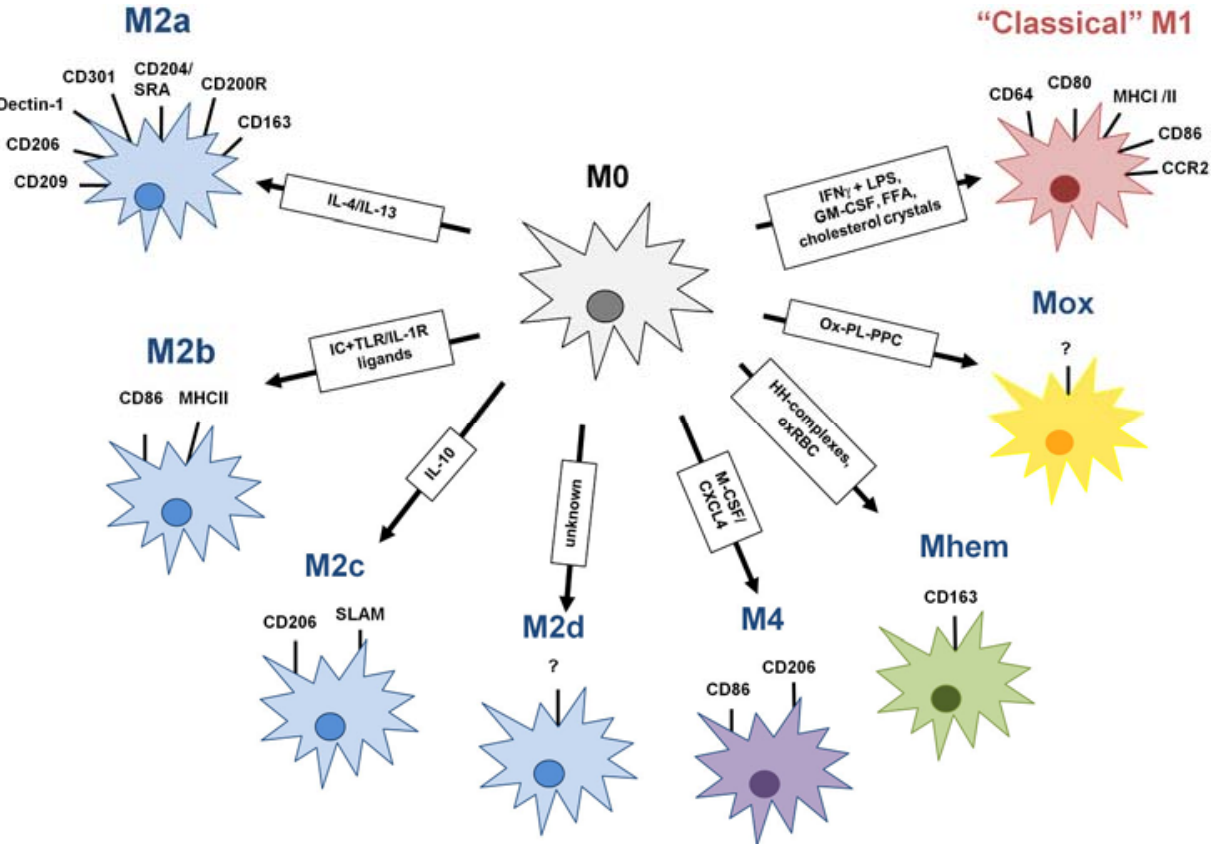

Fig. 1. Schematic representation of $\mathrm{M} \phi$ polarization. While $\mathrm{M} 1 /$ classically activated macrophages are typically induced by IFN $\gamma$ and microbial products like LPS, different stimuli lead to the development of an array of finely tuned alternately activated states. IC, Immune complex; HH, Haptohemoglobin; OxRBC, oxidized red blood cells; Ox-PL-PPC, ox-PL 1palmitoyl-2arachidonoyl-sn-glycero3-phosphorycholine; FFA, free fatty acid. of cytokine and JAK/STAT signaling, was found to increase levels of the M1 genes IL-1 $\beta$, IL-6, IL-12, IL-23, and iNOS (Qin et al., 2012a) and increase phosphorylation of STAT1 and STAT3 (Qin et al., 2012b).

In contrast, STAT6 is activated by IL-4 and IL-13 to induce M2 polarization (Daley et al., 2009; Moreno et al., 2003; Stolfi et al., 2011). C-Jun N-terminal kinase (JNK), a mitogen-activated protein kinase (MAPK) involved in cell proliferation, transformation, differentiation, and apoptosis is likely involved in this pathway (Zhou et al., 2013). Upon activation, JNK can phosphorylate serine 707 on STAT6, thereby deactivating it (Shirakawa et al., 2011). A study of $M \phi$ polarization in obesity showed that mice lacking the JNK activator MLK3 were also deficient in M1 $M \phi$ polarization (Gadang et al., 2013). The transcription factors PPAR $\gamma$ and PPAR $\delta$ are activated by STAT6 and necessary for M2 polarization, and PPAR $\delta^{-/} \mathrm{M} \phi$ exhibit enhanced activation of JNK following treatment with adipocyte-conditioned medium, which contains the M2 cytokines IL-4 and IL-13 (Kang et al., 2008; Odegaard et al., 2007). The zinc-finger transcriptional regulator Krüppel-like factor 4 (KLF4) is involved in this pathway as well and cooperates with STAT6 to skew polarization towards M2 by sequestering coactivators of NF-кB (Liao et al., 2011).

Furthermore, the phosphoinositol-3-kinase (PI3K) signaling pathway, which activates multiple kinase cascades through the production of the second messenger PIP3, regulates M $\phi$ survival and gene expression via activation of the Akt family of serine/threonine protein kinases (Liu et al., 2001; Luyendyk et al., 2008). Knockout studies have demonstrated that M1 polarization depends on the activation of Akt2 while M2 polarization requires Akt1 (Arranz et al., 2012). In addition, the PI3K/Akt signaling pathway controls the activation of mTOR, which promotes M2 polarization (Byles et al., 2013; Mercalli et al., 2013; Weichhart and Säemann, 2008).

Interferon-regulatory factor (IRF) proteins are also regulators of $\mathrm{M} \phi$ polarization. IRF5 is associated with $\mathrm{M} 1$ polarization and promotes the transcription of genes encoding IL-12 while re- pressing the gene that encodes IL-10 (Krausgruber et al., 2011). Notch signaling through the nuclear transducer RBP-J controls expression of IRF8, which induces M1 gene expression (Xu et al., 2012). IRF4 is highly expressed in adipose tissue $M \phi$ (ATM) and its deletion leads to increased production of $\mathrm{IL}-1 \beta$ and TNF $\alpha$ and expression of M1 markers, indicating that IRF4 activation contributes to M2 polarization (Eguchi et al., 2013). The IRFs also underlie the ability of GM-CSF and M-CSF to induce polarization: GM-CSF leads to downstream activation of IRF5 (M1) while M-CSF leads to IRF4 (M2) activation (Lawrence and Natoli, 2011).

\section{BACTERIAL INFECTIONS}

Given the ability of $M \phi$ to acquire enhanced microbicidal abilities following stimulation with microbial products and the preeminent roles of $\mathrm{M} \phi$ in both innate and adaptive immune responses, one might predict that pathogens would evolve strategies to redirect and alter $M \phi$ activation in their favor. Several transcriptome analysis studies have established that innate immune cells, particularly $M \phi$, engage in a common response to pathogen challenge that involves a shared pattern of gene expression (Jenner and Young, 2005; Nau et al., 2002). A multi-study review of transcriptional responses of mononuclear phagocytes to bacteria and bacterial components focusing specifically on genes involved in $\mathrm{M} \phi$ polarization identified a common response program that mainly involved the upregulation of M1associated genes, including the cytokines TNF, IL-6, IL-12, IL$1 \beta$, the cytokine receptors IL-7R and IL-15RA, the chemokines CCL2, CCL5, and CXCL8, and the chemokine receptor CCR7 (Benoit et al., 2008). This M1 activation program is typically associated with protection against disease, and M1 polarization has been shown to aid host control of several bacteria, including Listeria monocytogenes, Salmonella typhimurium, Mycobacterium tuberculosis, Mycobacterium ulcerans, and Chlamydia infections (Benoit et al., 2008; Chacón-Salinas et al., 2005; Jouanguy et al., 1999; Kiszewski et al., 2006; Rottenberg et al., 


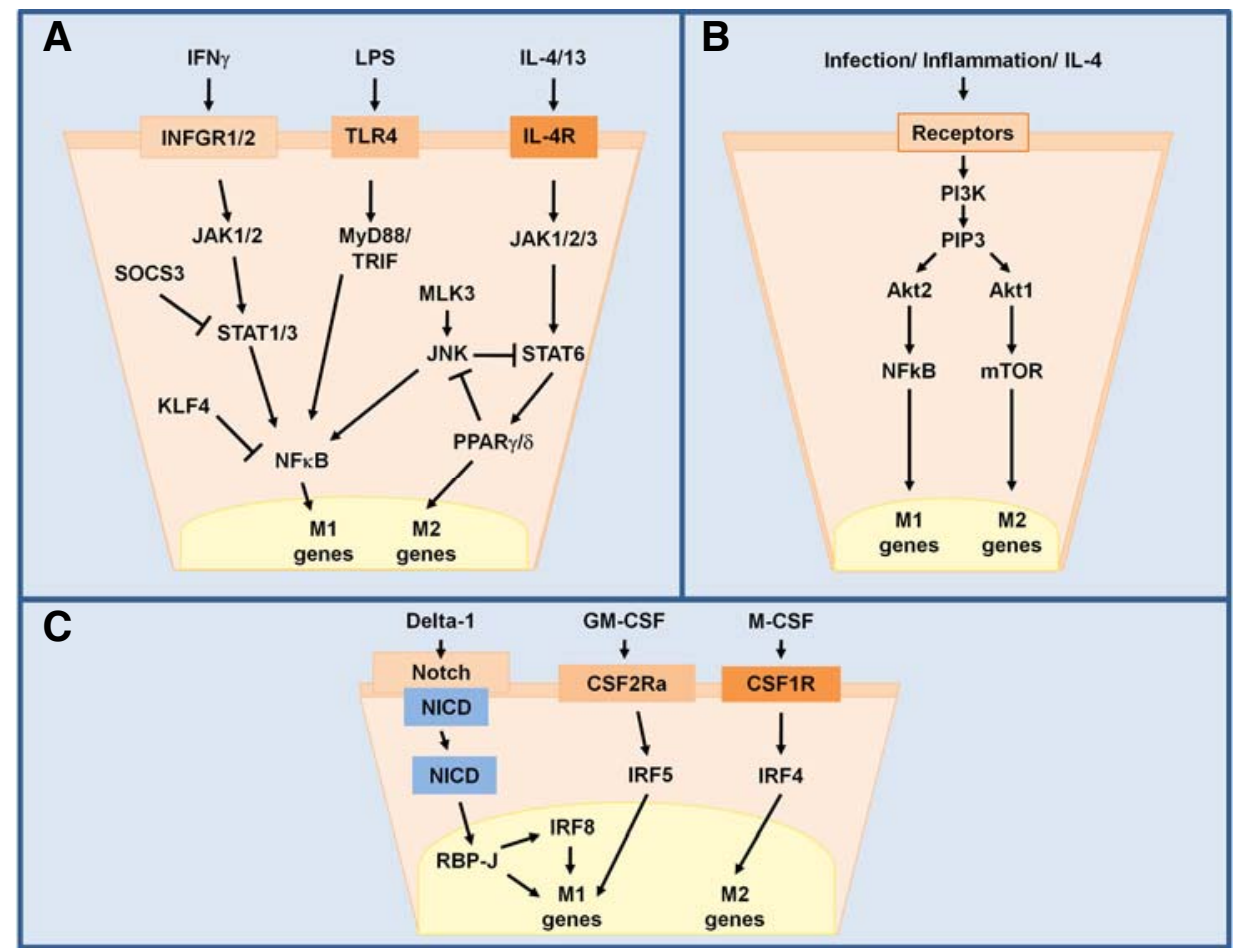

Fig. 2. Major signaling pathways involved in $\mathrm{M} 1 / \mathrm{M} 2 \mathrm{M} \phi$ polarization. STAT1/3 and STAT6 regulate transcription of $\mathrm{M} 1$ and $\mathrm{M} 2$ genes following recognition of IFN $\gamma$ or IL-4/13 by their surface receptors and activation of JAKs (A). Differential activation of Akt1 or Akt2 via PI3K and PIP3 leads to either M2 or M1 polarization, respecively (B). Upon activation, the intracellular domain of Notch (NICD) is cleaved and activates IRF8 to promote M1 polarization. GM-CSF triggers M1 polarization via IRF5 while M-CSF induces M2 polarization via IRF4 (C).

\section{2; Shaughnessy and Swanson, 2007).}

Consequently, several pathogenic bacteria, especially intracellular species, have developed mechanisms to interfere with $\mathrm{M} \phi$ polarization in order to enhance their own survival. Some species accomplish this by blunting M1 polarization to reduce inflammation and microbicidal functions of $\mathrm{M} \phi$. The intracellular form of the enteropathogen Shigella flexneri produces an altered, hypoacetylated form of LPS that evades recognition by TLR4 and elicits decreased production of proinflammatory cytokines from murine bone marrow derived $\mathrm{M} \phi$ (BMDM) (Paciello et al., 2013). During pulmonary infection in mice, Staphylococcus aureus induces Akt1 signaling to enhance SOCS1 activity and inhibit NF-KB activity, shifting $M \phi$ from an antimicrobial M1 phenotype to a functionally inert one ( $\mathrm{Xu}$ et al., 2013). M. tuberculosis secretes the virulence factors lipoarabinomannan and early secretory antigenic target-6 (ESAT-6), which inhibit M1 activation by inhibiting phagosome maturation and NF-KB activation, respectively (Lugo-Villarino et al., 2011). $M$. tuberculosis also subverts the inflammatory response by stimulating Wnt6 signaling in infected $M \phi$ in granulomatous lesions in the lung, driving M2-like polarization (Schaale et al., 2013). S. aureus biofilms are resistant to $M \phi$ invasion, but those $\mathrm{M} \phi$ that do successfully penetrate catheter-associated biofilms in vitro display decreased expression of IL-1 $\beta, T N F \alpha$, and iNOS expression but robust Arg1 expression, signifying an M2 profile (Thurlow et al., 2011). S. typhimurium has been shown to preferentially associate with $\mathrm{M} 2 \mathrm{M} \phi$, and PPAR $\delta$ expression is upregulated in Salmonella-infected $M \phi$ while PPAR $\delta$ deficiency severely inhibits bacterial replication and persistence (Eisele et al., 2013). Interestingly, the dependency of $S$. typhimurium on PPAR $\delta$ expression was shown to be due to its metabolic effects rather than its ability to reduce production of antimicrobial mediators by promoting M2 polarization, and it remains to be determined whether $S$. typhimurium directly augments PPAR $\delta$ activity to promote persistence.

\section{VIRAL INFECTIONS}

Similar to evasion strategies employed by bacterial pathogens, many viruses take advantage of the $M \phi$ polarization system to enhance their own growth and virulence. However, unlike bacterial pathogens, which generally tend to thrive within and encourage production of M2-polarized $\mathrm{M} \phi$, viral pathogens more commonly activate M1 polarization. This inflammatory phenotype is often correlated with disease severity. Hepatitis $C$ virus preferentially infects hepatocytes and establishes a chronic inflammatory infection, often leading to fibrotic cirrhosis and hepatocellular carcinoma (HCC) (Lavanchy, 2011). It has been demonstrated that the viral protein NS3 enhances IL-12 and TNFa production by THP-1 M $\phi$, implicating M1 polarization in sustaining inflammation (Hajizadeh et al., 2013). Furthermore, activation of $M \phi$ with TLR agonists triggers the secretion of $\mathrm{TNF} \alpha$, which promotes HCV entry into polarized hepatoma cells by relocalizing the tight junction protein and HCV entry factor occludin (Fletcher et al., 2013). Of the three common clades of avian $\mathrm{H} 5 \mathrm{~N} 1$ influenza virus circulating in poultry in China (2.3.2, 2.3.4, and 7), clade 2.3.4 is the most successful at infecting, replicating within, and inducing cytopathic effects in human monocyte-derived M $\phi$ (MDM) (Sun et al., 2013). H5N1 clade 2.3.4 also stimulated the highest expression of IL-1 $\beta$, IL-6, IL-8, TNF $\alpha$, IFN $\gamma$, and MCP-1 in MDMs (Sun et al., 2013). M2 $\mathrm{M} \phi$ polarization by $S$. aureus, which is commonly present among the airway mucosal microbiota, inhibits influenza-mediated lung injury, implying that $\mathrm{M} 1 \mathrm{M} \phi$ exacerbate flu infection (Wang et al., 2013).

Nonetheless, some viruses do benefit by skewing $\mathrm{M} \phi$ polarization towards an M2 phenotype. During infection by severe acute respiratory syndrome coronavirus (SARS-CoV), lung 
damage resulting from both intrinsic viral infection and dysregulation of the host immune response rapidly progresses to diffuse alveolar damage, resulting in acute respiratory distress syndrome and pulmonary fibrosis (Franks et al., 2003; Peiris et al., 2003). A recent study revealed that SARS-CoV-infected mice lacking hematopoeitic STAT1 expression have greater weight loss and lung pathology associated with upregulation of the M2 indicators YM1, FIZZ1, IL-4, and IL-13 (Page et al., 2012). Absence of lung disease and prefibrotic lesions in infected STAT1/STAT6 ${ }^{-/-}$double-knockout mice also supported the notion that M2 M $\phi$ contribute to SARS-CoV pathogenesis. Human cytomegalovirus (HCMV) has a more complex relationship with $\mathrm{M} \phi$ polarization. The HCMV gene UL111A encodes a homolog of human IL-10 that is capable of polarizing monocytes towards an anti-inflammatory M2c phenotype including high expression of the scavenger receptor CD163, suppression of MHC expression, and exppression of heme oxygenase 1 (which suppresses TNF $\alpha$ and IL-1 $\beta$ ) (Avdic et al., 2013). Additionally, HCMV optimally infects M2- but not M1-polarized $M \phi$ and latephase HCMV infection is dependent on the M2-promoting activation of mTOR (Poglitsch et al., 2012). Despite this, HCMVactivated $M \phi$ have been shown to adopt an $M 1$ transcriptome profile (Chan et al., 2008). HIV-1 similarly seems to benefit from M2 polarization: HIV-1 displays impaired viral DNA synthesis, delayed proviral integration, and reduced proviral transcription in $\mathrm{M} 1 \mathrm{M} \phi$, while the $\mathrm{M} 2 \mathrm{a}$ surface receptor DC-SIGN facilitates HIV-1 entry, DNA synthesis, and transmission from infected $M \phi$ to $\mathrm{CD}^{+}{ }^{+} \mathrm{T}$ cells (Cassetta et al., 2013; Cassol et al., 2010; 2013). Notably, clathrin-mediated endocytosis of HIV-1 is increased in $M 1$ and decreased in $M 2 M \phi$, but this method of endocytosis leads to increased viral degradation and is unlikely to result in productive infection (Gobeil et al., 2012). Yet, like HCMV, HIV-1 infection of MDMs drives them toward M1 polarization, and the viral protein Nef is preferentially taken up by $\mathrm{M} 2$ $\mathrm{M} \phi$ and stimulates an M2-to-M1 transition (Cassol et al., 2010; Chihara et al., 2012; Lugo-Villarino et al., 2011). These contradictions may be explained by a viral survival strategy that takes advantage of both $\mathrm{M} 1$ and $\mathrm{M} 2 \mathrm{M} \phi$ as means to different ends: $\mathrm{M} 2 \mathrm{M} \phi$ as a reservoir of replication and $\mathrm{M} 1 \mathrm{M} \phi$ to recruit fresh immune cells to spread the infection. This can also be inferred from the ability of proinflammatory cytokines and chemokines from $\mathrm{HCMV}$-infected $\mathrm{M} \phi$ to enhance virus replication and dissemination (Alfano et al., 2013; Smith and Bentz, 2004a; 2004b).

\section{DIABETES, OBESITY, AND NON-ALCOHOLIC STEATOHEPATITIS}

Type 1 diabetes is an autoimmune disease that results in high blood sugar following the destruction of insulin-producing pancreatic beta cells via activation of innate immunity and expansion of auto-reactive $T$ cells and autoantibody-producing $B$ cells. Monocytes/M $\mathrm{M}$ from patients with Type 1 diabetes present a proinflammatory profile (high levels of TNF $\alpha$, IL-6 and IL-1 $1 \beta$ ) when compared to normal subjects (Bradshaw et al., 2009; Devaraj et al., 2006; Shanmugam et al., 2004). Moreover, elevated levels of glucose and islet amyloid polypeptide (IAPP) deposition lead to the activation of TLRs and inflammasomes, resulting in beta cell death and decreased insulin secretion (Henao-Mejia et al., 2013). Recently, it has been suggested that M1 M $\phi$ may contribute to diabetes-related complications such as cardiovascular diseases by altering the immune system of type 1 diabetics (Burke and Kolodgie, 2004). Furthermore, the sustained increase of growth hormone in murine models of type 1 diabetes leads to a reduction of diabetes symptoms by attenuating the apoptosis and increasing the expansion of beta cells (Villares et al., 2013). Growth hormone also triggers $\mathrm{M} 2$ polarization of $\mathrm{M} \phi$ via modulation of the cytokine milieu, stimulating the activity of suppressor $\mathrm{T}$ cells and limiting Th17 cell activation (Villares et al., 2013).

Obesity is a major health problem in western countries and a risk factor for insulin resistance, type 2 diabetes, hepatic steatosis, and artherosclerosis. Obesity is closely associated with chronic inflammation in adipose tissues, suggesting that the chronic excess of nutrients triggers an immune response in adipose tissues (Goh et al., 2011; Hotamisligil, 2006; Kanneganti and Dixit, 2012). White adipose tissues store energy in the form of fat and regulate systemic metabolism through the release of adipokines by adipocytes that control insulin sensitivity in the liver and skeletal muscle (Sun et al., 2011; Tateya et al., 2013). In lean subjects and mice, adipose tissue $M \phi$ (ATM) present an M2 phenotype and are critical to maintaining insulin sensitivity in adipocytes through IL-10 production (Liao et al., 2011; Lumeng et al., 2007a; 2007b). In metabolic homeostasis, M2 ATMs are maintained by IL-4 and IL-13 secreted by adipocytes in a PPAR $\gamma / \delta / \beta$ - and KLF4-dependent manner (Wynn et al., 2013; Zhou et al., 2013). In obese subjects and mice, adipocytes release proinflammatory mediators (i.e. CCL2/MCP-1, TNF $\alpha$, CCL5, CCL8 and free fatty acid), promoting the infiltration of Ly6C ${ }^{\text {hi }}$ inflammatory monocytes which differentiate into M1-polarized ATMs that express high levels of TNF $\alpha$, iNOS, IL6 and IL-1 $\beta$ (Cinti et al., 2005; Lumeng et al., 2007a; Olefsky and Glass, 2010; Tateya et al., 2013; Weisberg et al., 2003, 2006). Therefore, the severity of obesity-related metabolic dysfunctions correlates with M1 ATM infiltration whereas chronic inflammation in adipose tissue inhibits the production of adiponectin, thus contributing to the development of insulin resistance in surrounding adipocytes (Lumeng et al., 2007a; Weisberg et al., 2003; 2006).

Recently NAFLD (Non-alcoholic fatty liver disease) has emerged as an obesity-related health problem characterized by steatosis (accumulation of lipids in hepatocytes). Hepatic steatosis can evolve to non-alcoholic steatohepatitis (NASH) when accompanied by liver injury (ballooning hepatocytes) and hepatic inflammation, which may be associated with fibrosis and eventually culminates in cirrhosis and HCC. The development of the complex pathology of NASH involves a variety of liver cells including hepatocytes, hepatic $\mathrm{M} \phi$, and stellate cells. Inflammatory mediators, especially those derived from adipose tissues, the gut, and the liver, have recently been reported to play a major role in initiating and controlling the progression of NASH by regulating lipid metabolism (Day and James, 1998; Racanelli and Rehermann, 2006; Tilg and Moschen, 2010). In particular, the activation of innate immune cells such as Kupffer cells and infiltrating blood-derived monocytes is a major event of NASH development. In homeostatic conditions, Kupffer cells perform immune surveillance by removing pathogens and toxins from the circulation and maintain liver tolerance through IL10 secretion (Thomson and Knolle, 2010). Kupffer cells communicate with a variety of hepatic immune cells and interact directly with hepatocytes passing through the space of Disse (Racanelli and Rehermann, 2006). In early mouse models of diet-induced steatohepatitis, Kupffer cells are the first innate cells responding to injured hepatocytes and differentiate toward $\mathrm{M} 1 \mathrm{M} \phi$, promoting the recruitment of blood-derived CD11 $\mathrm{b}^{\text {int }}$ Ly6C ${ }^{\text {hi }}$ monocytes through secretion of TNF $\alpha$ and chemokines (MCP-1 and IP-10) (Tosello-Trampont et al., 2012). The recruitment of these inflammatory M1-polarized Ly6C $\mathrm{C}^{+}$blood-derived monocytes is dependent of CCR2 and MCP1 (Karlmark et al., 
2009; Klein et al., 2007; Miura et al., 2012; Obstfeld et al., 2010). The hallmarks of NASH (i.e. steatosis, low-grade inflammation, and hepatic recruitment of $\mathrm{M} 1$-polarized $\mathrm{M} \phi$ ) are reduced/delayed following specific depletion of Kupffer cells or by silencing of TNF $\alpha$ in myeloid cells (Tosello-Trampont et al., 2012). Moreover, M1-polarized Kupffer cells also produce inflammatory mediators such as IL-1 $\beta$ and ROS, which induce hepatic steatosis and fibrosis (Miura et al., 2012; Schwabe and Brenner, 2006). NF-KB and JNK activation in Kupffer cells may contribute to the development of hepatic inflammation by promoting M1-like M $\phi$ polarization (Zhou et al., 2013).

Liver $\mathrm{M} \phi$ are also implicated in the severity of $\mathrm{NASH}$ via the expression of Toll-like receptors (TLR2, TLR4, TLR9, MyD88) and scavenger receptors (scavenger receptor $A$ and CD36) (Bieghs et al., 2010; Miura et al., 2010; 2012; 2013). TLRs and scavenger receptors trigger proinflammatory responses following recognition of hepatic free fatty acids, damage-associated molecular pattern (DAMPs) expressed by steatotic hepatocytes, and/or bacterial products derived from the gut (Farrell et al., 2012; Roh and Seki, 2013). NASH patients show increased intestinal permeability, resulting in greater hepatic abundance of bacterial products and other TLR ligands derived from the gut via portal vein circulation (Zhu et al., 2013). The imbalance of gut flora may influence liver disease by activating TLRs expressed on liver cells and leading to the activation of NLPR3 (Csak et al., 2011; Farrell et al., 2012; Henao-Mejia et al., 2013; Roh and Seki, 2013). In models of diet-induced NASH and obesity, inflammasome-deficient mice develop more severe NASH which is fully transferable to WT mice upon prolonged cohousing, suggesting that commensal bacteria in the Gl tract play an important role in NASH disease progression (Csak et al., 2011; Henao-Mejia et al., 2012; 2013; Weisberg et al., 2003).

\section{CANCER}

$\mathrm{M} \phi$ are a highly influential cell type in most varieties of cancer and are recruited to all solid tumors (Cassetta et al., 2011). The contributions of different subsets of polarized $M \phi$ to the tumor microenvironment and cancer progression are therefore a subject of great interest. $\mathrm{M} 1 \mathrm{M} \phi$ are generally considered to be beneficial to the host, and peritumoral $M \phi$ that express M1 cytokines like IFN $\gamma, \mathrm{IL}-1 \beta$, and IL- 6 have been shown to have antitumoral effects and are associated with improved prognoses (Dumont et al., 2008; Klimp et al., 2002; Niino et al., 2010; Öberg et al., 2002; Zhou et al., 2010). M1 M $\phi$ may have the opposite effect in virally induced cancers, however: administration of IFN $\gamma$ or TNF $\alpha$ to patients infected with Kaposi sarcoma virus enhances disease progression (Monini et al., 1999). Proinflammatory $M \phi$ are also harmful in intraocular tumors, where TNF $\alpha$ - and iNOS-dependent antitumor responses lead to necrosis of bystander cells and destruction of the eye (Coursey et al., 2012).

M2-polarized tumor-associated $\mathrm{M} \phi$ (TAM), on the other hand, have been repeatedly and consistently associated with unfavorable effects like tumor growth, angiogenesis, and metastasis in malignant cancers (Alfano et al., 2013). The M2 cytokines IL$4, \mathrm{IL}-13$, and IL-10 are present within the tumor microenvironment and TAMs from various cancer models have been shown to express an M2 activation profile that includes enhanced expression of CD163, MRC-1, c-type lectins, IL-10, and Arg-1 and decreased production of IL-12 (Beck et al., 2009; Biswas et al., 2006; Schmieder et al., 2012; Sica et al., 2002). The small secretory lectin Reg3 $\beta$ is an important inhibitor of inflammation in pancreatic and intestinal tissues, and deficiency of Reg3 $\beta$ (an activator of the STAT3 pathway) drastically impairs pancreatic tumor growth by skewing $\mathrm{M} \phi$ polarization away from $\mathrm{M} 2$ and towards M1 (Gironella et al., 2013). M2 TAMs have also been shown to increase fibroblastic morphology, vimentin and snail expression, metalloproteinase activity, and proliferation and migration of pancreatic cancer cells, implicating them in the development of eptihelial-mesenchymal transition and metastasis (Liu et al., 2013). In HCC, high expression of the heparinsulfate proteoglycan glypican-3 (GPC3) on the surface of cancer cells is associated with increased $M \phi$ infiltration in human patients, and human/mouse xenograft transplantation with a GPC3-overexpressing cell line leads to infiltration by $M \phi$ expressing M2-specific markers (Takai et al., 2009a; 2009b). M2 TAMs worsen HCC both by promoting tumor growth and angiogenesis and by encouraging liver fibrosis through IL-13 and TGF $\beta$ secretion (Sica et al., 2013).

\section{THERAPIES TARGETING M $\Phi$ POLARIZATION}

Given that $\mathrm{M} \phi$ play important roles in maintaining tissue homeostasis and fighting disease, polarized $M \phi$ subsets that specifically contribute to the pathogenesis or amelioration of various diseases present themselves as attractive targets for therapeutic intervention. Different therapeutic strategies include either targeting the polarized $M \phi$ themselves or manipulating the signaling pathways involved in the process of $M \phi$ polarization to a desirable outcome.

Bacterial biofilms that form on body surfaces or on surgical implants lead to chronic and recurrent infections, and are difficult to treat with antibiotics (Donlan and Costerton, 2002; Otto, 2008). Early, local administration of $\mathrm{M} 1 \mathrm{M} \phi$ or the C5a receptor agonist EP67, which stimulates M1 polarization, significantly attenuated biofilm formation in a mouse model (Hanke et al., 2013). Furthermore, treatment of established biofilms significantly reduced bacterial burden compared to antibiotic treatment, suggesting the potential of a therapeutic alternative (Hanke et al., 2013). Microbes themselves may also prove to be useful sources of therapeutics that modulate $\mathrm{M} \phi$ polarization. In vitro application of extracellular polysaccharide secreted by an oligotrophic bacteria found in Lop Nur Desert, Bacillus sp. LBP32, was found to limit LPS-induced inflammation in the $M \phi$ cell line RAW 264.7 by inhibiting NF- $\kappa B$ and JNK activation, and may prove useful in diseases characterized by excessive M1 polarization (Diao et al., 2013). Similarly, the small-molecule compound bis- $N$-norgliovictin isolated from the marine-derived endophytic fungus S3-1-c inhibits LPS-induced M1 polarization of RAW 264.7 cells and murine peritoneal $M \phi$, and improves survival in mouse models of sepsis (Song et al., 2013). As a proof of concept for treating inflammatory gastrointestinal diseases, a lab strain of $E$. coli was created that secretes a Herpes virus homolog of IL-10 via a Sec-dependent transporter construct. Viral IL-10 delivered in this manner was shown to activate STAT3 and suppress TNF $\alpha$ production in the J774.1 murine M $\phi$ cell line (Förster et al., 2013).

IKK $\beta$, a downstream mediator of insulin resistance and activator of the NF-kB pathway (and therefore of M1 polarization), is inhibited by anti-inflammatory salicylates like aspirin, which attenuates hyperglycemia and hyperinsulinemia in obese rodents (Yin et al., 1998; Yuan et al., 2001). Several small trials in patients with type 2 diabetes have demonstrated that treatment with salicylates results in a marked reduction of diabetic metabolic parameters and improved glycemic control (Tateya et al., 2013).

Apolipoprotein A-I mimetics are a class of therapeutic mole- 
cules that attempt to modulate HDL to treat atherosclerosis and are the subject of extensive clinical and mechanistic study, as reviewed in Leman et al. (2013). Interestingly, the mimetic D4F also has potential for cancer therapy: D4F inhibits the M2associated scavenger receptor CD204/SRA on TAMs, preventing metastatic spread (Neyen et al., 2013).

Anticancer therapies also seek to convert protumoral $\mathrm{M} 2 \mathrm{M} \phi$ into $M 1 M \phi . M 2 M \phi$ generated by IL-6 and prostaglandin $E_{2}$ secreted by cervical cancer cells can be repolarized to $\mathrm{M} 1$ by coculture with Th1 cells, and this interaction could possibly be reproduced by activation with CD40L and IFN $\gamma$ (Heusinkveld et al., 2011). Moreover, IFN $\gamma$ was shown to successfully switch M2 TAMs purified from human ovarian tumors to an M1 phenotype, and the addition of IFN $\gamma$ skewed de novo tumor-induced M2 differentiation of monocytes to favor M1 polarization (Duluc et al., 2009). Other potentially therapeutic molecules found to repolarize TAMs from an M2 to an M1 phenotype include zoledronic acid, CpG oligonucleotide, and histidine-rich glycoprotein (Coscia et al., 2010; Huang et al., 2012; Rolny et al., 2011).

\section{CONCLUSION}

The integral importance of $M \phi$ in the maintenance of nearly every tissue throughout the body and their position as the first line of defense against many diseases guarantees that they play critical roles in both disease progression and in resolution, and that altering the behavior of these cells can mean the difference between healthy recovery and severe illness. M $\phi$ polarization itself is an extremely nuanced and fine-tuned process and can produce nearly infinite variations of endpoint phenotypes, each of which has the potential to affect various diseases in different ways. While polarized $\mathrm{M} \phi$ subsets and the polarization process itself are attractive and novel therapeutic targets in both infectious and inflammatory disease, better understanding of how polarization is controlled and how polarized $\mathrm{M} \phi$ modulate specific diseases is necessary to fully harness the potential of these strategies.

\section{ACKNOWLEDGMENTS}

This work was supported by NIH grants R01Al098126 and U19AI066328.

\section{REFERENCES}

Alfano, M., Graziano, F., Genovese, L., and Poli, G. (2013). Macrophage polarization at the crossroad between HIV-1 infection and cancer development. Arterioscler. Throm. Vas. Biol. 33, 11451152.

Arranz, A., Doxaki, C., Vergadi, E., de la Torre, Y.M., Vaporidi, K., Lagoudaki, E.D., leronymaki, E., Androulidaki, A., Venihaki, M., Margioris, A.N., et al. (2012). Akt1 and Akt2 protein kinases differentially contribute to macrophage polarization. Proc. Natl. Acad. Sci. USA 109, 9517-9522.

Avdic, S., Cao, J.Z., McSharry, B.P., Clancy, L.E., Brown, R., Steain, M., Gottlieb, D., Abendroth, A., and Slobedman, B. (2013). Human cytomegalovirus interleukin-10 polarizes monocytes toward a deactivated M2c phenotype to repress host immune responses. J. Virol. 87, 10273-1082.

Beck, A.H., Espinosa, I., Edris, B., Li, R., Montgomery, K., Zhu, S., Varma, S., Marinelli, R.J., van de Rijn, M., and West, R.B. (2009). The macrophage colony-stimulating factor 1 response signature in breast carcinoma. Clin. Cancer Res. 15, 778-787.

Benoit, M., Desnues, B., and Mege, J.-L. (2008). Macrophage polarization in bacterial infections. J. Immunol. 181, 3733-3739.

Bieghs, V., Wouters, K., van Gorp, P.J., Gijbels, M.J.J., de Winther, M.P.J., Binder, C.J., Lütjohann, D., Febbraio, M., Moore, K.J., van Bilsen, M., et al. (2010). Role of scavenger receptor $A$ and CD36 in diet-induced nonalcoholic steatohepatitis in hyperlipi- demic mice. Gastroenterology 138, 2477-2486, 2486.e1-e3.

Biswas, S.K., and Mantovani, A. (2010). Macrophage plasticity and interaction with lymphocyte subsets: cancer as a paradigm. Nat. Immunol. 11, 889-896.

Biswas, S.K., Gangi, L., Paul, S., Schioppa, T., Saccani, A., Sironi, M., Bottazzi, B., Doni, A., Vincenzo, B., Pasqualini, F., et al. (2006). $A$ distinct and unique transcriptional program expressed by tumor-associated macrophages (defective NF-kappaB and enhanced IRF-3/STAT1 activation). Blood 107, 2112-22.

Biswas, S.K., Sica, A., and Lewis, C.E. (2008). Plasticity of macrophage function during tumor progression: regulation by distinct molecular mechanisms. J. Immunol. 180, 2011-2017.

Bradshaw, E.M., Raddassi, K., Elyaman, W., Orban, T., Gottlieb, P. A., Kent, S.C., and Hafler, D.A. (2009). Monocytes from patients with type 1 diabetes spontaneously secrete proinflammatory cytokines inducing Th17 cells. J. Immunol. 183, 4432-4439.

Burke, A.P., Kolodgie, F.D., Zieske, A., Fowler, D.R., Weber, D.K., Varghese, P.J., Farb, A., and Virmani, R. (2004). Morphologic findings of coronary atherosclerotic plaques in diabetics: a postmortem study. Arterioscler. Throm. Vas. Biol. 24, 1266-1271.

Byles, V., Covarrubias, A.J., Ben-Sahra, I., Lamming, D.W., Sabatini, D.M., Manning, B.D., and Horng, T. (2013). The TSC-mTOR pathway regulates macrophage polarization. Nat. Commun. 4, 2834.

Cassetta, L., Cassol, E., and Poli, G. (2011). Macrophage polarization in health and disease. ScientificWorldJournal 11, 2391-2402.

Cassetta, L., Kajaste-Rudnitski, A., Coradin, T., Saba, E., Della Chiara, G., Barbagallo, M., Graziano, F., Alfano, M., Cassol, E., Vicenzi, E., et al. (2013). M1 polarization of human monocytederived macrophages restricts pre and postintegration steps of HIV-1 replication. AIDS 27, 1847-1856.

Cassol, E., Cassetta, L., Alfano, M., and Poli, G. (2010). Macrophage polarization and HIV-1 infection. J. Leukoc. Biol. 87, 599-608.

Cassol, E., Cassetta, L., Rizzi, C., Gabuzda, D., Alfano, M., and Poli, G. (2013). Dendritic cell-specific intercellular adhesion molecule3 grabbing nonintegrin mediates HIV-1 infection of and transmission by M2a-polarized macrophages in vitro. AIDS 27, 707716.

Chacón-Salinas, R., Serafín-López, J., Ramos-Payán, R., MéndezAragón, P., Hernández-Pando, R., Van Soolingen, D., FloresRomo, L., Estrada-Parra, S., and Estrada-García, I. (2005). Differential pattern of cytokine expression by macrophages infected in vitro with different Mycobacterium tuberculosis genotypes. Clin. Exp. Immunol. 140, 443-449.

Chan, G., Bivins-Smith, E.R., Smith, M.S., Smith, P.M., and Yurochko, A.D. (2008). Transcriptome analysis reveals human cytomegalovirus reprograms monocyte differentiation toward an M1 macrophage. J. Immunol. 181, 698-711.

Chang, N.C., Hung, S.I., Hwa, K.Y., Kato, I., Chen, J.E., Liu, C.H., and Chang, A.C. (2001). A macrophage protein, Ym1, transiently expressed during inflammation is a novel mammalian lectin. $\mathrm{J}$. Biol. Chem. 276, 17497-17506.

Chihara, T., Hashimoto, M., Osman, A., Hiyoshi-Yoshidomi, Y., Suzu, I., Chutiwitoonchai, N., Hiyoshi, M., Okada, S., and Suzu, S. (2012). HIV-1 proteins preferentially activate anti-inflammatory M2-type macrophages. J. Immunol. 188, 3620-3627.

Cinti, S., Mitchell, G., Barbatelli, G., Murano, I., Ceresi, E., Faloia, E., Wang, S., Fortier, M., Greenberg, A.S., and Obin, M.S. (2005). Adipocyte death defines macrophage localization and function in adipose tissue of obese mice and humans. J. Lipid Res. 46, 2347-2355.

Coscia, M., Quaglino, E., lezzi, M., Curcio, C., Pantaleoni, F., Riganti, C., Holen, I., Mönkkönen, H., Boccadoro, M., Forni, G., et al. (2010). Zoledronic acid repolarizes tumour-associated macrophages and inhibits mammary carcinogenesis by targeting the mevalonate pathway. J. Cell. Mol. Med. 14, 2803-2815.

Coursey, T.G., Chen, P.W., and Niederkorn, J.Y. (2012). Abrogating TNF- $\alpha$ expression prevents bystander destruction of normal itssues diruing iNOS-mediated elimination of intraocular tumors. Cancer Res. 71, 2445-2454.

Csak, T., Ganz, M., Pespisa, J., Kodys, K., Dolganiuc, A., and Szabo, G. (2011). Fatty acid and endotoxin activate inflammasomes in mouse hepatocytes that release danger signals to stimulate immune cells. Hepatology 54, 133-144.

Daley, J.M., Brancato, S.K., Thomay, A.A., Reichner, J.S., and Albina, J.E. (2009). The phenotype of murine wound macropha- 
ges. J. Leukoc. Biol. 87, 59-67.

Davies, L.C., Jenkins, S.J., Allen, J.E., and Taylor, P.R. (2013) Tissue-resident macrophages. Nat. Immunol. 14, 986-995.

Day, C.P., and James, O.F. (1998). Steatohepatitis: a tale of two "hits"? Gastroenterology 114, 842-845.

Devaraj, S., Glaser, N., Griffen, S., Wang-Polagruto, J., Miguelino, E., and Jialal, I. (2006). Increased monocytic activity and biomarkers of inflammation in patients with type 1 diabetes. Diabetes 55, 774-779.

Diao, Y., Xin, Y., Zhou, Y., Li, N., Pan, X., Qi, S., Qi, Z., Xu, Y., Luo, L., Wan, H., et al. (2013). Extracellular polysaccharide from Bacillus sp. strain LBP32 prevents LPS-induced inflammation in RAW 264.7 macrophages by inhibiting NF- $\kappa \mathrm{B}$ and MAPKs activation and ROS production. Int. Immunopharmacol. 18, 12-19.

Donlan, R., and Costerton, J. (2002). Biofilms: survival mechanisms of clinically relevant microorganisms. Clin. Microbiol. Rev. 15, 167193.

Duffield, J. (2005). Selective depletion of macrophages reveals distinct, opposing roles during liver injury and repair. J. Clin. Invest. 115, 56-65.

Duluc, D., Corvaisier, M., Blanchard, S., Catala, L., Descamps, P. Gamelin, E., Ponsoda, S., Delneste, Y, Hebbar, M., and Jeannin, $P$. (2009). Interferon-gamma reverses the immunosuppressive and protumoral properties and prevents the generation of human tumor-associated macrophages. Int. J. Cancer 125, 367-373.

Dumont, P., Berton, A., Nagy, N., Sandras, F., Tinton, S., Demetter P., Mascart, F., Allaoui, A., Decaestecker, C., and Salmon, I. (2008). Expression of galectin-3 in the tumor immune response in colon cancer. Lab. Invest. 88, 896-906.

Eguchi, J., Kong, X., Tenta, M., Wang, X., Kang, S., and Rosen, E. D. (2013). Interferon regulatory factor 4 regulates obesity-induced inflammation through regulation of adipose tissue macrophage polarization. Diabetes 62, 3394-3403.

Eisele, N.A, Ruby, T., Jacobson, A., Manzanillo, P.S., Cox, J.S. Lam, L., Mukundan, L., Chawla, A., and Monack, D.M. (2013) Salmonella require the fatty acid regulator PPAR $\delta$ for the establishment of a metabolic environment essential for long-term persistence. Cell Host Microbe 14, 171-182.

Farrell, G.C., Chitturi, S., Gan, L., and van Rooyen, D. (2012). NASH is an inflammatory disorder: pathogenic, prognostic and therapeutic implications. Gut Liver 6, 149-171.

Fenyo, I.M., and Gafencu, A.V. (2013). The involvement of the monocytes/macrophages in chronic inflammation associated with atherosclerosis. Immunobiology 218, 1376-1384

Fletcher, N., Sutaria, R., Jo, J., and Barnes, A. (2013). Activated macrophages promote hepatitis $C$ virus entry in a tumor necrosis factor-dependent manner. Hepatology (in press).

Förster, S., Brandt, M., Mottok, D.S., Zschüttig, A., Zimmermann, K., Blattner, F.R., Gunzer, F., and Pöhlmann, C. (2013). Secretory expression of biologically active human Herpes virus interleukin10 analogues in Escherichia coli via a modified Sec-dependent transporter construct. BMC Biotechnol., 13, 82.

Franks, T.J., Chong, P.Y., Chui, P., Galvin, J.R., Lourens, R.M., Reid, A.H., Selbs, E., Mcevoy, P.L., Hayden, D.L., Fukuoka, J., et al. (2003). Lung pathology of severe acute respiratory syndrome (SARS): a study of 8 autopsy cases from Singapore. Hum. Pathol. 34, 743-748.

Gadang, V., Kohli, R., Myronovych, A., Hui, D.Y., Perez-Tilve, D. and Jaeschke, A. (2013). MLK3 promotes metabolic dysfunction induced by saturated fatty acid-enriched diet. Am. J. Physiol. Endoc. Metab. 305, E549-556

Gautier, E. L., Shay, T., Miller, J., Greter, M., Jakubzick, C., Ivanov, S., Helft, J., Chow, A., Elpek, K. G., Gordonov, S., et al. (2012) Gene-expression profiles and transcriptional regulatory pathways that underlie the identity and diversity of mouse tissue macrophages. Nat. Immunol. 13, 1118-1128.

Ghavami, S., Shojaei, S., Yeganeh, B., Ande, S.R., Jangamreddy, J.R., Mehrpour, M., Christoffersson, J., Chaabane, W., Moghadam, A.R., Kashani, H.H., et al. (2014). Autophagy and apoptosis dysfunction in neurodegenerative disorders. Prog. Neurobiol. 112, 24-49.

Gironella, M., Calvo, C., Fernández, A., Closa, D., Iovanna, J.L., Rosello-Catafau, J., and Folch-Puy, E. (2013). Reg3 $\beta$ deficiency impairs pancreatic tumor growth by skewing macrophage polarization. Cancer Res. 73, 5682-5694.

Gobeil, L.A., Lodge, R., and Tremblay, M.J. (2012). Differential HIV-
1 endocytosis and susceptibility to virus infection in human macrophages correlate with cell activation status. J. Virol. 86, 10399-10407.

Goh, Y.P.S., Chawla, A., and Nguyen, K.D. (2011). Macrophagemediated inflammation in metabolic disease. Nat. Rev. Immunol. $11,738-749$

Gomez Perdiguero, E., and Geissmann, F. (2013). Myb-independent macrophages: a family of cells that develops with their tissue of residence and is involved in its homeostasis. Cold Spring Harb. Symp. Quant. Biol. [Epub ahead of print].

Gordon, S. (2003). Alternative activation of macrophages. Nat. Rev. Immunol. 3, 23-35.

Hajizadeh, M.R., Mokarram, P., Kamali-Sarvestani, E., Bolhassani, A., and Mostafavi-Pour, Z. (2013). Recombinant nonstructural 3 protein, rNS3, of hepatitis C virus along with recombinant GP96 induce IL-12, TNF $\alpha$ and $\alpha 5$ integrin expression in antigen presenting cells. Hepat. Mon. 13, e8104

Hanke, M.L., Heim, C.E., Angle, A., Sanderson, S.D., and Kielian, T. (2013). Targeting macrophage activation for the prevention and treatment of Staphylococcus aureus biofilm infections. J. Immunol. 190, 2159-2168.

Henao-Mejia, J., Elinav, E., Jin, C., Hao, L., Mehal, W.Z., Strowig T., Thaiss, C.A., Kau, A.L., Eisenbarth, S.C., Jurczak, M.J., et al (2012). Inflammasome-mediated dysbiosis regulates progression of NAFLD and obesity. Nature 482, 179-185.

Henao-Mejia, J., Elinav, E., Thaiss, C.A., and Flavell, R.A. (2013). Inflammasomes and metabolic disease. Annu. Rev. Physiol. [Epub ahead of print]

Heusinkveld, M., de Vos van Steenwijk, P.J., Goedemans, R Ramwadhdoebe, T.H., Gorter, A., Welters, M.J.P., van Hall, T., and van der Burg, S.H. (2011). M2 macrophages induced by prosta-glandin E2 and IL-6 from cervical carcinoma are switched to activated M1 macrophages by $\mathrm{CD}^{+}$Th1 cells. J. Immunol. 187, 1157-1165.

Heydtmann, M. (2009). Macrophages in hepatitis B and hepatitis C virus infections. J. Virol. 83, 2796-2802.

Hotamisligil, G.S. (2006). Inflammation and metabolic disorders. Nature 444, 860-867.

Hu, X., Chen, J., Wang, L., and Ivashkiv, L.B. (2007). Crosstalk among Jak-STAT, Toll-like receptor, and ITAM-dependent pathways in macrophage activation. J. Leukoc. Biol. 82, 237-243.

Huang, Z., Zhang, Z., Jiang, Y., Zhang, D., Chen, J., Dong, L., and Zhang, J. (2012). Targeted delivery of oligonucleotides into tumorassociated macrophages for cancer immunotherapy. J. Control Release 158, 286-292

Hume, D.A. (2008). Differentiation and heterogeneity in the mononuclear phagocyte system. Mucosal Immunol. 1, 432-441.

Jenner, R.G., and Young, R.A. (2005). Insights into host responses against pathogens from transcriptional profiling. Nat. Rev. Microbiol. 3, 281-294.

Ji, W.J., Ma, Y.Q., Zhou, X, Zhang, Y.D., Lu, R.Y., Sun, H.Y., Guo, Z.Z., Zhang, Z., Li, Y.M., and Wei, L.Q. (2013). Temporal and spatial characterization of mononuclear phagocytes in circulating, lung alveolar and interstitial compartments in a mouse model of bleomycin-induced pulmonary injury. J. Immunol. Methods pii: S0022-1759(13)00328-1.

Jouanguy, E., Döffinger, R., Dupuis, S., Pallier, A., Altare, F., and Casanova, J.L. (1999). IL-12 and IFN- $\gamma$ in host defense against mycobacteria and salmonella in mice and men. Curr. Opin. Immunol. 11, 346-351.

Kadl, A., Meher, A.K., Sharma, P.R., Lee, M.Y., Doran, A.C., Johnstone, S.R., Elliot, M.R., Gruber, F., Han, J., Chen, W., et al. (2010). Identification of a novel macrophage phenotype that develops in response to atherogenic phospholipids via Nrf2. Cir. Res. 107 737-746.

Kang, K., Reilly, S.M., Karabacak, V., Gangl, M.R., Fitzgerald, K., Hatano, B., and Lee, C.-H. (2008). Adipocyte-derived Th2 cytokines and myeloid PPARdelta regulate macrophage polarization and insulin sensitivity. Cell Metab. 7, 485-495.

Kanneganti, T.D., and Dixit, V.D. (2012). Immunological complications of obesity. Nat. Immunol. 13, 707-712

Karlmark, K.R., Weiskirchen, R., Zimmermann, H.W., Gassler, N. Ginhoux, F., Weber, C., Merad, M., Luedde, T., Trautwein, C., and Tacke, F. (2009). Hepatic recruitment of the inflammatory Gr1+ monocyte subset upon liver injury promotes hepatic fibrosis. Hepatology 50, 261-274. 
Kiszewski, A.E., Becerril, E., Aguilar, L.D., Kader, I.T.A., Myers, W., Portaels, F., and Hernàndez Pando, R. (2006). The local immune response in ulcerative lesions of Buruli disease. Clin. Exp. Immunol. 143, 445-451.

Klein, I., Cornejo, J.C., Polakos, N.K., John, B., Wuensch, S.A Topham, D.J., Pierce, R.H., and Crispe, I.N. (2007). Kupffer cell heterogeneity: functional properties of bone marrow derived and sessile hepatic macrophages. Blood 110, 4077-4085.

Klimp, A.H., de Vries, E.G.E., Scherphof, G.L., and Daemen, T. (2002). A potential role of macrophage activation in the treatment of cancer. Crit. Rev. Oncol. Hematol. 44, 143-161.

Krausgruber, T., Blazek, K., Smallie, T., Alzabin, S., Lockstone, H., Sahgal, N., Hussell, T., Feldmann, M., and Udalova, I.A. (2011). IRF5 promotes inflammatory macrophage polarization and TH1TH17 responses. Nat. Immunol. 12, 231-238.

Lavanchy, D. (2011). Evolving epidemiology of hepatitis C virus. Clin. Microbiol. Infect. 17, 107-115.

Lawrence, T., and Natoli, G. (2011). Transcriptional regulation of macrophage polarization: enabling diversity with identity. Nat. Rev. Immunol. 11, 750-761.

Leitinger, N., and Schulman, I.G. (2013). Phenotypic polarization of macrophages in atherosclerosis. Arterioscler. Throm. Vas. Biol. 33, $1120-1126$.

Leman, L.J., Maryanoff, B.E., and Ghadiri, M.R. (2013). Molecules that mimic apolipoprotein A-I: potential agents for treating Atherosclerosis. J. Med. Chem. (in press)

Liao, X., Sharma, N., and Kapadia, F. (2011). Krüppel-like factor 4 regulates macrophage polarization. J. Clin. Invest. 121, 2736-2749.

Liu, H., Perlman, H., Pagliari, L.J., and Pope, R.M. (2001). Constitutively activated Akt-1 is vital for the survival of human monocyte-differentiated macrophages. Role of Mcl-1, independent of nuclear factor (NF)-kappaB, Bad, or caspase activation J. Exp. Med. 194, 113-126.

Liu, C.Y., Xu, J.Y., Shi, X.Y., Huang, W., Ruan, T.Y., Xie, P., and Ding, J.L. (2013). M2-polarized tumor-associated macrophages promoted epithelial-mesenchymal transition in pancreatic cancer cells, partially through TLR4/IL-10 signaling pathway. Lab. Invest. $93,844-854$

Lugo-Villarino, G., Vérollet, C., Maridonneau-Parini, I., and Neyrolles, O. (2011). Macrophage polarization: convergence point targeted by Mycobacterium tuberculosis and HIV. Front. Immunol. 2, 43.

Lumeng, C.N., Bodzin, J.L., and Saltiel, A.R. (2007a). Obesity induces a phenotypic switch in adipose tissue macrophage polarization. J. Clin. Invest. 117, 175-184.

Lumeng, C.N., Deyoung, S.M., Bodzin, J.L., and Saltiel, A.R. (2007b) Increased inflammatory properties of adipose tissue macrophages recruited during diet-induced obesity. Diabetes 56,16 23.

Luyendyk, J.P., Schabbauer, G.A., Tencati, M., Holscher, T., Pawlinski, R., and Mackman, N. (2008). Genetic analysis of the role of the PI3K-Akt pathway in lipopolysaccharide-induced cytokine and tissue factor gene expression in monocytes/macrophages. J. Immunol. 180, 4218-4226.

Majai, G., Kiss, E., Tarr, T., Zahuczky, G., Hartman, Z., Szegedi, G., and Fésüs, L. (2014). Decreased apopto-phagocytic gene expression in the macrophages of systemic lupus erythematosus patients. Lupus 23, 133-145.

Mantovani, A., Sica, A., Sozzani, S., Allavena, P., Vecchi, A., and Locati, M. (2004). The chemokine system in diverse forms of macrophage activation and polarization. Trends Immunol. 25 677-686.

Mantovani, A., Biswas, S.K., Galdiero, M.R., Sica, A., and Locati, M. (2013). Macrophage plasticity and polarization in tissue repair and remodelling. J. Pathol. 229, 176-185.

Martinez, F.O., Sica, A., Mantovani, A., and Locati, M. (2008). Macrophage activation and polarization. Front. Biosci. 13, 453-461.

Martinez, F.O., Helming, L., and Gordon, S. (2009). Alternative activation of macrophages: an immunologic functional perspective. Annu. Rev. Immunol. 27, 451-483.

Mercalli, A., Calavita, I., Dugnani, E., Citro, A., Cantarelli, E., Nano, R., Melzi, R., Maffi, P., Secchi, A., Sordi, V., et al. (2013). Rapamycin unbalances the polarization of human macrophages to M1. Immunology 140, 179-190.

Mills, C.D., Kincaid, K., Alt, J.M., Heilman, M.J., and Hill, A.M. (2000) $\mathrm{M}-1 / \mathrm{M}-2$ macrophages and the Th1/Th2 paradigm. J. Immunol.
164, 6166-6173.

Miura, K, Kodama, Y., Inokuchi, S., Schnabl, B., Aoyama, T., Ohnishi, H., Olefsky, J.M., Brenner, D.A., and Seki, E. (2010). Toll-Like Receptor 9 Promotes Steatohepatitis by Induction of Interleukin-1 beta in mice. Gastroenterology 139, 323-U453.

Miura, K., Yang, L., van Rooijen, N., Ohnishi, H., and Seki, E. (2012). Hepatic recruitment of macrophages promotes nonalcoholic steatohepatitis through CCR2. Am. J. Physiol. Gastrointest. Liver Physiol. 302, G1310-G1321.

Miura, K., Yang, L., van Rooijen, N., Brenner, D.A., Ohnishi, H., and Seki, E. (2013). Toll-like receptor 2 and palmitic acid cooperatively contribute to the development of nonalcoholic steatohepatitis through inflammasome activation in mice. Hepatology 57, 577-589.

Monini, P., Colombini, S., Stürzl, M., Goletti, D., Cafaro, A., Sgadari, C., Buttò, S., Franco, M., Leone, P., Fais, S., et al. (1999). Reactivation and persistence of human herpesvirus-8 infection in $\mathrm{B}$ cells and monocytes by Th-1 cytokines increased in Kaposi's sarcoma. Blood 93, 4044-4058.

Moreno, J.L., Kaczmarek, M., Keegan, A.D., and Tondravi, M. (2003). IL-4 suppresses osteoclast development and mature osteoclast function by a STAT6-dependent mechanism: irreversible inhibition of the differentiation program activated by RANKL. Blood 102, 1078-1086.

Mosser, D. (2003). The many faces of macrophage activation. J. Leukoc. Biol. 73, 209-212.

Mosser, D.M., and Edwards, J.P. (2008). Exploring the full spectrum of macrophage activation. Nat. Rev. Immunol. 8, 958-969.

Murray, P.J., and Wynn, T.A. (2011). Protective and pathogenic functions of macrophage subsets. Nat. Rev. Immunol. 11, 723737.

Mylonas, K.J., Nair, M.G., Prieto-Lafuente, L., Paape, D., and Allen, J.E. (2009). Alternatively activated macrophages elicited by helminth infection can be reprogrammed to enable microbial killing. J. Immunol. 182, 3084-3094.

Nau, G.J., Richmond, J.F.L., Schlesinger, A., Jennings, E.G., Lander, E.S., and Young, R.A. (2002). Human macrophage activation programs induced by bacterial pathogens. Proc. Natl. Acad. Sci. USA 99, 1503-1508.

Neyen, C., Mukhopadhyay, S., Gordon, S., and Hagemann, T. (2013). An apolipoprotein A-I mimetic targets scavenger receptor A on tumor-associated macrophages: a prospective anticancer treatment? Oncoimmunology 2, e24461.

Niino, D., Komohara, Y., Murayama, T., Aoki, R., Kimura, Y., Hashikawa, K., Kiyasu, J., Takeuchi, M., Suefuji, N., Sugita, Y., et al. (2010). Ratio of M2 macrophage expression is closely associated with poor prognosis for Angioimmunoblastic T-cell lymphoma (AITL). Pathol. Int. 60, 278-283.

Öberg, Å., Samii, S., Stenling, R., and Lindmark, G. (2002). Different occurrence of CD8+, CD45R0+, and CD68+ immune cells in regional lymph node metastases from colorectal cancer as potential prognostic predictors. Int. J. Colorectal Dis. 17, 25-29.

Obstfeld, A.E., Sugaru, E., Thearle, M., Francisco, A.M., Gayet, C., Ginsberg, H.N., Ables, E.V., and Ferrante, A.W. (2010). C-C chemokine receptor 2 (CCR2) regulates the hepatic recruitment of myeloid cells that promote obesity-induced hepatic steatosis. Diabetes 59, 916-925.

Odegaard, J.I., Ricardo-Gonzalez, R.R., Goforth, M.H., Morel, C.R., Subramanian, V., Mukundan, L., Red Eagle, A., Vats, D., Brombacher, F., Ferrante, A.W., et al. (2007). Macrophage-specific PPARgamma controls alternative activation and improves insulin resistance. Nature 447, 1116-1120.

Olefsky, J.M., and Glass, C.K. (2010). Macrophages, inflammation, and insulin resistance. Annu. Rev. Physiol. 72, 219-246.

Otto, M. (2008). Staphylococcal biofilms. Curr. Top. Microbiol. Immunol. 322, 207-228.

Paciello, I., Silipo, A., Lembo-fazio, L., Curcurù, L., Zumsteg, A., Noël, G., Ciancarella, V., Sturiale, L., Molinaro, A., and Bernardini, M.L. (2013). Intracellular Shigella remodels its LPS to dampen the innate immune recognition and evade inflammasome activation. Proc. Natl. Acad. Sci. USA 110, E4345-4354.

Page, C., Goicochea, L., Matthews, K., Zhang, Y., Klover, P., Holtzman, M.J., Hennighausen, L., and Frieman, M. (2012). Induction of alternatively activated macrophages enhances pathogenesis during severe acute respiratory syndrome coronavirus infection J. Virol. 86, 13334-13349. 
Peiris, J.S.M., Chu, C.M., Cheng, V.C.C., Chan, K.S., Hung, I.F.N., Poon, L.L.M., Law, K.I., Tang, B.S., Hon, T.Y., Chan, C.S., et al. (2003). Clinical progression and viral load in a community outbreak of coronavirus-associated SARS pneumonia: a prospective study. Lancet 361, 1767-1772.

Poglitsch, M., Weichhart, T., Hecking, M., Werzowa, J., Katholnig, K., Antlanger, M., Krmpotic, A, Jonjic, S., Hörl, W.H., Zlabinger, G.J., et al. (2012). CMV late phase-induced mTOR activation is essential for efficient virus replication in polarized human macrophages. Am. J. Transplant. 12, 1458-1468.

Qin, H., Holdbrooks, A.T., Liu, Y., Reynolds, S.L., Yanagisawa, L.L., and Benveniste, E.N. (2012a). SOCS3 deficiency promotes M1 macrophage polarization and inflammation. J. Immunol. 189, 3439-3448.

Qin, H., Yeh, W.I., De Sarno, P., Holdbrooks, A.T., Liu, Y., Muldowney, M.T., Reynolds, S.L., Yanagisawa, L.L., Fox, T.H., Park, $\mathrm{K}$., et al. (2012b). Signal transducer and activator of transcription-3/suppressor of cytokine signaling-3 (STAT3/SOCS3) axis in myeloid cells regulates neuroinflammation. Proc. Natl. Acad. Sci. USA 109, 5004-5009.

Racanelli, V., and Rehermann, B. (2006). The liver as an immunological organ. Hepatology 43, S54-S62.

Raes, G., De Baetselier, P., Noël, W., Beschin, A., Brombacher, F., and Hassanzadeh Gh, G. (2002). Differential expression of FIZZ1 and Ym1 in alternatively versus classically activated macrophages. J. Leukoc. Biol. 71, 597-602.

Raes, G., Van den Bergh, R., De Baetselier, P., Ghassabeh, G.H., Scotton, C., Locati, M., Mantovani, A., and Sozzani, S. (2005). Arginase-1 and Ym1 are markers for murine, but not human alternatively activated myeloid cells. J. Immunol. 174, 6561-6562.

Rauch, I., Müller, M., and Decker, T. (2013). The regulation of inflammation by interferons and their STATs. JAKSTAT 2, e23820.

Rawlings, J.S., Rosler, K.M., and Harrison, D.A. (2004). The JAKI STAT signaling pathway. J. Cell Sci. 117, 1281-1283.

Rius, B., López-Vicario, C., González-Périz, A., Morán-Salvador, E., García-Alonso, V., Clária, J., and Titos, E. (2012). Resolution of inflammation in obesity-induced liver disease. Front. Immunol. 3, 257.

Roh, Y.S., and Seki, E. (2013). Toll-like receptors in alcoholic liver disease, non-alcoholic steatohepatitis and carcinogenesis. J. Gastroenterol. Hepatol. 28, 38-42.

Rolny, C., Mazzone, M., Tugues, S., Laoui, D., Johansson, I., Coulon, C., Sguadrito, M.L., Segura, I., Li, X., Knevels, E., et al. (2011). HRG inhibits tumor growth and metastasis by inducing macrophage polarization and vessel normalization through downregulation of PIGF. Cancer Cell 19, 31-44.

Rottenberg, M.E., Gigliotti-Rothfuchs, A., and Wigzell, H. (2002) The role of IFN-gamma in the outcome of chlamydial infection. Curr. Opin. Immunol. 14, 444-451.

Schaale, K., Brandenburg, J., Kispert, A., Leitges, M., Ehlers, S., and Reiling, N. (2013). Wnt6 is expressed in granulomatous lesions of mycobacterium tuberculosis-infected mice and is in volved in macrophage differentiation and proliferation. J. Immunol. 191, 5182-5195.

Schmieder, A., Michel, J., Schönhaar, K., Goerdt, S., and Schledzewski, K. (2012). Differentiation and gene expression profile of tumor-associated macrophages. Semin. Cancer. Biol. 22, 289297.

Schulz, C., Gomez Perdiguero, E., Chorro, L., Szabo-Rogers, H., Cagnard, N., Kierdorf, K., Prinz, M., Wu, B., Jacobsen, S.E., Pollard, J.W., et al. (2012). A lineage of myeloid cells independent of Myb and Hematopoietic stem cells. Science 336, 86-90.

Schwabe, R.F., and Brenner, D.A. (2006). Mechanisms of liver injury. I. TNF-alpha-induced liver injury: role of IKK, JNK, and ROS pathways. Am. J. Physiol. Gastrointest. Liver Physiol. 290, G583-G589.

Schwabe, R.F., Seki, E., and Brenner, D.A. (2006). Toll-like receptor signaling in the liver. Gastroenterology 130, 1886-900.

Shanmugam, N., Gaw Gonzalo, I.T., and Natarajan, R. (2004) Molecular mechanisms of high glucose-induced cyclooxygenase-2 expression in monocytes. Diabetes 53, 795-802.

Shaughnessy, L.M., and Swanson, J.A. (2007). The role of the activated macrophage in clearing Listeria monocytogenes infection. Front. Biosci. 12, 2683-2692.

Shirakawa, T., Kawazoe, Y., Tsujikawa, T., Jung, D., Sato, S., and Uesugi, M. (2011). Deactivation of STAT6 through serine 707 phosphorylation by JNK. J. Biol. Chem. 286, 4003-4010.

Sica, A., and Mantovani, A. (2012). Macrophage plasticity and polarization: in vivo veritas. J. Clin. Invest. 22, 787-795.

Sica, A., Saccani, A., and Mantovani, A. (2002). Tumor-associated macrophages: a molecular perspective. Int. Immunopharmacol. 2, 1045-1054

Sica, A, Invernizzi, P., and Mantovani, A. (2013). Macrophage plasticity and polarization in liver homeostasis and pathology. Hepatology [In Press].

Smith, M., and Bentz, G. (2004a). Human cytomegalovirus induces monocyte differentiation and migration as a strategy for dissemination and persistence. J. Virol. 78, 4444-4453.

Smith, M., and Bentz, G. (2004b). HCMV activates PI (3) K in monocytes and promotes monocyte motility and transendothelial migration in a PI (3) K-dependent manner. J. Leukoc. Biol. 76, 65-76.

Song, Y., Dou, H., Gong, W., Liu, X., Yu, Z., Li, E., Tan, R., and Hou, Y. (2013). Bis-N-norgliovictin, a small-molecule compound from marine fungus, inhibits LPS-induced inflammation in macrophages and improves survival in sepsis. Eur. J. Pharmacol. 705, 49-60.

Stolfi, C., Caruso, R., Franzè, E., Sarra, M., De Nitto, D., Rizzo, A., Pallone, F., and Monteleone, G. (2011). Interleukin-25 fails to activate STAT6 and induce alternatively activated macrophages. Immunology 132, 66-77.

Stout, R.D., Jiang, C., Matta, B., Tietzel, I., Watkins, S.K., and Suttles, J. (2005). Macrophages sequentially change their functional phenotype in response to changes in microenvironmental influences. J. Immunol. 175, 342-349.

Stout, R.D., and Suttles, J. (2004). Functional plasticity of macrophages: reversible adaptation to changing microenvironments. J. Leukoc. Biol. 76, 509-513.

Sun, K., Kusminski, C.M., and Scherer, P.E. (2011). Adipose tissue remodeling and obesity. J. Clin. Invest. 121, 2094-2101.

Sun, H., Sun, Y., Pu, J., Zhang, Y., Zhu, Q., Li, J., Gu, J., Chang, K. C., and Liu, J. (2013). Comparative virus replication and host innate response in human cells infected with 3 prevalent clades $(2.3 .4,2.3 .2$ and 7$)$ of highly pathogenic avian influenza H5N1 viruses. J. Virol. 88, 725-729.

Takai, H., Ashihara, M., Ishiguro, T., Terashima, H., Watanabe, T., Kato, A., and Suzuki, M. (2009a). Involvement of glypican-3 in the recruitment of M2-polarized tumor-associated macrophages in hepatocellular carcinoma. Cancer Biol. Ther. 8, 2329-2338.

Takai, H., Kato, A., Kato, C., Watanabe, T., Matsubara, K., Suzuki, M., and Kataoka, H. (2009b). The expression profile of glypican3 and its relation to macrophage population in human hepatocellular carcinoma. Liver Int. 29, 1056-1064.

Tateya, S., Kim, F., and Tamori, Y. (2013). Recent advances in obesity-induced inflammation and insulin resistance. Front. Endocrinol. 4, 93.

Thomson, A.W., and Knolle, P.A. (2010). Antigen-presenting cell function in the tolerogenic liver environment. Nat. Rev. Immunol. $10,753-766$

Thurlow, L.R., Hanke, M.L., Fritz, T., Angle, A., Aldrich, A., Williams, S.H., Engebretsen, I.L., Bayles, K.W., Horswill, A.R., and Kielian, T. (2011). Staphylococcus aureus biofilms prevent macrophage phagocytosis and attenuate inflammation in vivo. J. Immunol. 186, 6585-6596.

Tilg, H., and Moschen, A.R. (2010). Evolution of inflammation in nonalcoholic fatty liver disease: the multiple parallel hits hypothesis. Hepatology 52, 1836-1846.

Tosello-Trampont, A.C., Landes, S.G., Nguyen, V., Novobrantseva, T.I., and Hahn, Y.S. (2012). Kuppfer cells trigger nonalcoholic steatohepatitis development in diet-induced mouse model through tumor necrosis factor-a production. J. Biol. Chem. 287, 40161-40172.

Umemura, N., Saio, M., Suwa, T., Kitoh, Y., Bai, J., Nonaka, K., Ouyang, G.F., Okada, M., Balazs, M., Adany, R., et al. (2008). Tumorinfiltrating myeloid-derived suppressor cells are pleiotropicinflamed monocytes/macrophages that bear M1- and M2-type characteristics. J. Leukoc. Biol. 83, 1136-1144.

Verreck, F.A., de Boer, T., Langenberg, D.M., Hoeve, M.A., Kramer, M., Vaisberg, E., Kastelein, R., Kolk, A., de Wall-Malefyt, R., and Ottenhoff, T.H. (2004). Human IL-23-producing type 1 macrophages promote but IL-10-producing type 2 macrophages subvert immunity to (myco)bacteria. Proc. Natl. Acad. Sci. USA 101 
4560-4565.

Villares, R., Kakabadse, D., Juarranz, Y., Gomariz, R.P., MartínezA.C., and Mellado, M. (2013). Growth hormone prevents the development of autoimmune diabetes. Proc. Natl. Acad. Sci. USA $101,4619-4627$.

Wang, J., Li, F., Sun, R., Gao, X., Wei, H., Li, L.-J., and Tian, Z. (2013). Bacterial colonization dampens influenza-mediated acute lung injury via induction of $\mathrm{M} 2$ alveolar macrophages. Nat. Commun. 4, 2106.

Weichhart, T., and Säemann, M.D. (2008). The PI3K/Akt/mTOR pathway in innate immune cells: emerging therapeutic applications. Ann. Rheum. Dis. 67 Supp/ 3, iii70-4.

Weisberg, S.P., McCann, D., Desai, M., Rosenbaum, M., Leibel, R.L., and Ferrante, A.W. (2003). Obesity is associated with macrophage accumulation in adipose tissue. J. Clin. Invest. 112, 1796-1808.

Weisberg, S.P., Hunter, D., Huber, R., Lemieux, J., Slaymaker, S., Vaddi, K., Charo, I., Leibel, R.L., and Ferrante, A.W. (2006). CCR2 modulates inflammatory and metabolic effects of high-fat feeding. J. Clin. Invest. 116, 115-124.

Wynn, T.A., Chawla, A., and Pollard, J.W. (2013). Macrophage biology in development, homeostasis and disease. Nature 496 445-455.

Xu, H., Zhu, J., Smith, S., Foldi, J., Zhao, B., Chung, A.Y., Oultz, H. Kitajewski, J., Shi, C., Weber, S., et al. (2012). Notch-RBP-J signaling regulates the transcription factor IRF8 to promote inflammatory macrophage polarization. Nat. Immunol. 13, 642-650.
Xu, F., Kang, Y., Zhang, H., Piao, Z., Yin, H., Diao, R., Xia, J., and Shi, L. (2013). Akt1-mediated regulation of macrophage polarization in a murine model of Staphylococcus aureus pulmonary infection. J. Infect. Dis. 208, 528-538.

Yin, M.J., Yamamoto, Y., and Gaynor, R.B. (1998). The anti-inflammatory agents aspirin and salicylate inhibit the activity of I(kappa)B kinase-beta. Nature 396, 77-80.

You, Q., Holt, M., Yin, H., Li, G., Hu, C.-J., and Ju, C. (2013). Role of hepatic resident and infiltrating macrophages in liver repair after acute injury. Biochem. Pharmacol. 86, 836-843.

Yuan, M., Konstantopoulos, N., Lee, J., Hansen, L., Li, Z.W., Karin, M., and Shoelson, S.E. (2001). Reversal of obesity- and dietinduced insulin resistance with salicylates or targeted disruption of lkkbeta. Science 293, 1673-1677.

Zhou, Q., Peng, R.-Q., Wu, X.-J., Xia, Q., Hou, J.-H., Ding, Y., Zhou, Q.M., Zhang, X., Pang, Z.Z., Wan, D.S., et al. (2010). The density of macrophages in the invasive front is inversely correlated to liver metastasis in colon cancer. J. Transl. Med. 8, 13.

Zhou, D., Huang, C., Lin, Z., Zhan, S., Kong, L., Fang, C., and Li, J. (2013). Macrophage polarization and function with emphasis on the evolving roles of coordinated regulation of cellular signaling pathways. Cell. Signal. 26, 192-197.

Zhu, L., Baker, S.S., Gill, C., Liu, W., Alkhouri, R., Baker, R.D., and Gill, S.R. (2013). Characterization of gut microbiomes in nonalcoholic steatohepatitis (NASH) patients: a connection between endogenous alcohol and NASH. Hepatology 57, 601-609. 